\title{
Study on the Impact of Turbine Controls on Transient Stability of Synchronous Machine
}

\author{
Akhil S. Menon ${ }^{1}$, N. Ramesh Babu ${ }^{1, *}$ and Sreedhar Desabhatla ${ }^{2}$ \\ ${ }^{1}$ School of Electrical Engineering, VIT University, Vellore, India-632014 \\ ${ }^{2}$ GE Power, General Electric, Garching b. Munchen-85748, Germany \\ E-mail: akhilsmenon1991@gmail.com;nrameshbabu@vit.ac.in; \\ Sreedhar.Desabhatla@ge.com \\ *Corresponding Author
}

Received 29 August 2016; Accepted 11 November 2016;

Publication 22 November 2016

\begin{abstract}
This article discusses the work carried out in the development, validation and verification of the Turbine/Governor model (GGOV1) in GE Control Systems Toolbox ${ }^{\circledR}$ to comprehend the impact of Turbine controls post system transient. Simulation related studies are carried out using the model developed. MATLAB ${ }^{\circledR} /$ Simulink ${ }^{\circledR}$ has been used as the platform for validating the model. The validated model is replicated in the GE Control System Toolbox ${ }^{\circledR}$, for enhanced grid Simulation related studies. Comparative analysis of results obtained in both platforms with the validated parameters has been accomplished.
\end{abstract}

Keywords: GGOV1 Turbine/Governor model, Frequency transient, MATLAB ${ }^{\circledR} /$ Simulink ${ }^{\circledR}$, GE Control Systems Toolbox ${ }^{\circledR}$, Gas Turbine.

\section{Introduction}

In studies related to Power System, the Turbine/Governor models mainly deal with overall stability of the system. Stability related experiments concentrate

Journal of Green Engineering, Vol. 6_2, 1-22.

doi: $10.13052 /$ jge 1904-4720.624

(c) 2016 River Publishers. All rights reserved. 


\section{A. S. Menon et al.}

on areas like the transient rotor angle stability, voltage stability, frequency stability \& small signal stability. Definitions of each of the above mentioned stability related issues are given in [1]. In reality, these stability issues are interrelated. In most of the smaller systems, a single grid related event can create multiple allied issues of voltage, angular, and frequency stability.

Therefore, Turbine/Governor modelling is one of the key criteria required for investigations on previously mentioned stability issues, and to a limited extent for small signal stability. Regarding this last mentioned area, negative damping effect for the rotor oscillations will be there for the Turbine/Governor models in the required range of frequency. In synchronous generators, using PSS [2,3] damping can me improved for different modes of rotor oscillations. Proper tuning of PSS avoids such negative damping issues. High gain based automatic voltage regulators are one of influential source of negative damping problem [2].

The turbine-governor is very important for carrying out transient rotor angle stability related studies. In the initial second or two after a disturbance at the grid, the dynamics of Turbine/Governor model is of great importance. For the modelling required for transient stability related studies, the controls affecting the mechanical output during a grid fault are critical. One of the latest technologies used for regulating the frequency transients in grid, thereby maintain the output power, is through the implementation of pitch angle controller [9, 12] or a pitch blade controller [10] which is designed using a conventional PI controller. Acceleration controls [27] provided for gas turbine is another example for the above mentioned case. Acceleration control is mandatory for gas turbines. Provisions like implementation of droop control [11] through electrical power feedback, use of PI or PID controller in the controls of turbine governor (very common on modern gas turbine models) have effect on the transient stability. Active \& reactive power regulation for turbines is nowadays provided through variable universe fuzzy controller (VUFC) [13], PI controllers \& Direct Power Control [DPC] [18]. Therefore, modelling has to be carried out accordingly. In micro grid applications also, PI controllers are widely used for the regulation of frequency transients [16].

Turbine/Governor models also play a very important role in frequency stability. In power system performance, frequency response plays a critical role. Depending on the amount of Megawatt loss, Load characteristics, System Inertia, load loss, System droop, and the online responsive generation, system's actual frequency response will be varying from each and every event. Load frequency control for Gas Turbines can be done using PI controllers which is developed and tuned through Genetic Algorithm method (GA), Ziegler Nichols' method (ZN), and Fuzzy Gain Scheduling method 
(FGS) [14]. Fractional order proportional integral controller (FOPI) [15] which can be operated in full load region along with ensuring reliability \& performance required for integrating into the electric grid, gives more accurate performance compared to PI controllers, by introducing a tuning parameter known as the integral fractional-order.

As mentioned above, another important aspect of Turbine/Governor dynamics is the initial response of the Turbine Governor in the initial second or two, following any of the above mentioned grid disturbances.

With all the above mentioned cases, it can be understood that providing the exact specification required for the model performance for all study cases are difficult. Generally, we can say that, for typical planning related studies, the main intention is to simulate events where system can stay intact predominantly. For large systems like that in North America, the deviation in frequency in typical cases is maximum $\pm 1 \%$ with $0.3 \mathrm{~Hz} / \mathrm{s}$ as the maximum initial rate change. For smaller island systems, the deviation in frequency will be maximum of $\pm 5 \%$ with 1 to $2 \mathrm{~Hz} / \mathrm{s}$ as the maximum initial rate change.

Therefore, with behalf of the time scale of interest, the type of the model and its validation requirement can be decided.

\section{Methodology}

The GGOV1 model [4] structure shown in Figure 1, was developed in a collaborative effort involving GE Power and Water (then GE Energy) and Energy Consulting staff in the late 1990's. This model released by GE is an open source model used for dynamic simulation based research studies, that has been widely accepted by various international electrical systems councils like IEEE [4], CIGRE [4] and WECC [8]. Also, GGOV1 is one among the leading Turbine/Governor model that is still available in the commonly used simulation based programs/tools. Hence, various new models developed or being developed for modelling hydro turbines, modern combine cycle power plants \& thermal turbine governors are consolidated by comparing with the performance of this model. Hence, this model has been used for the dynamic simulation based studies shown in this paper. This paper does not claim to comment or address any grid codes or standards. Developing this Turbine/Governor Control Model in GE Control Systems Toolbox ${ }^{\circledR}$, would help to integrate to Electrical Models, for more accurate Simulation studies. MATLAB ${ }^{\circledR} /$ Simulink ${ }^{\circledR}$ is been used as the design platform for the studies required. These models have been replicated in the GE Control System Toolbox ${ }^{\circledR}$, for enhanced simulation studies such as analysing the impact of 


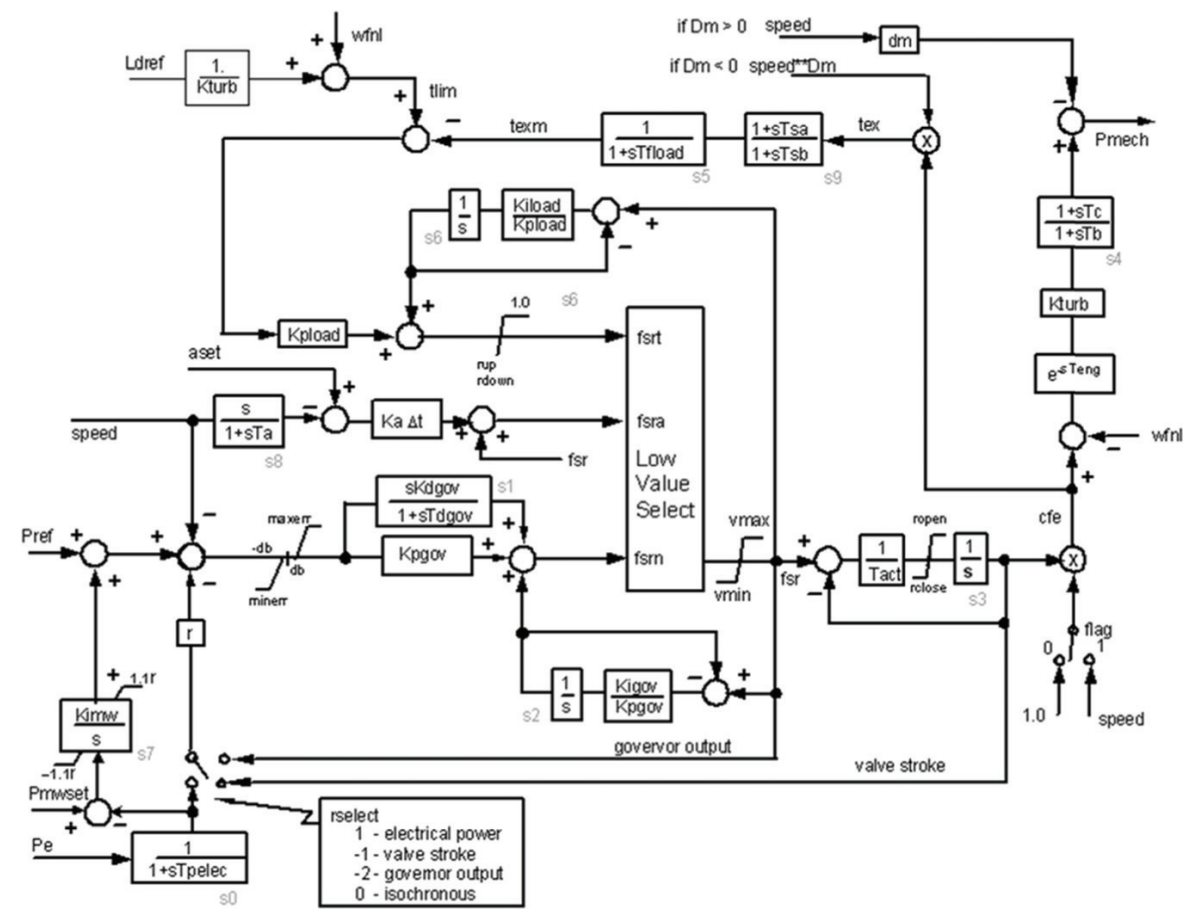

Figure 1 GGOV1 model structure [4].

mechanical power modulation during an excursion in power system. The proposed statements of the work are to validate the Governor models in Simulink ${ }^{\circledR}$, where the models are provided and to develop the equivalent code in GE Controls Platform, and to validate the accuracy of response of GE Toolbox with that of MATLAB ${ }^{\circledR} /$ Simulink $^{\circledR}$.

\subsection{Model Description}

The GGOV1 Turbine/governor model developed is a general - Purpose Turbine/Governor model which is used for carrying out dynamic Simulation related studies. This model is not at all a detailed thermodynamic treatment. It is a representation having simplified linear transfer function.

In terms of gas turbine, simplifying assumptions $[5,6]$ are made for the model as follows:

- IGVs (Inlet Guide Vanes) are neglected.

- A temperature limit or load limit as a constant has been assumed.

- No explicit representation of ambient or other effects. 
As IGV's are neglected, it will result in an assumption, that is, the only parameter defining the generation of power will be fuel flow. So, mechanical power at steady state $\left(\mathrm{P}_{\text {mech }}\right)$ developed from GGOV1 Turbine/Governor model is given by the following equation:

$$
\mathrm{P}_{\text {mech }}=\mathrm{K}_{\mathrm{turb}} *\left(\mathrm{~W}_{\mathrm{f}}-\mathrm{W}_{\mathrm{fnl}}\right)
$$

Where,

$\mathrm{W}_{\mathrm{f}}=$ Fuel flow at full speed, loaded conditions

$\mathrm{W}_{\mathrm{fnl}}=$ Fuel flow at full speed, no load conditions

$\mathrm{K}_{\text {turb }}=$ Turbine gain

The main feature of this model is its flexibility for providing different control options and signals for feedback, namely:

- PID control provided for speed error signal produced by speed reference, speed, and droop signal.

- PI control provided for the speed error signal produced by speed reference, speed and droop signal.

- P control provided for the speed error signal produced by speed reference and speed.

Droop signal [7] is obtained many feedback signals namely, electric power, valve stroke or governor output. In the last case of control design where proportional control is provided, the reciprocal for proportional gain will define droop. No other signal is required for defining droop. The guidelines required for Modelling of GT is provided in [8,21-24]. Also, experimental empirical transfer function models for gas turbines (GT) can be done [17].

\section{Implementation}

\subsection{Development}

The GE GGOV1 Turbine/Governor model discussed above was primarily built in MATLAB ${ }^{\circledR} /$ Simulink ${ }^{\circledR}$. MATLAB ${ }^{\circledR} /$ Simulink ${ }^{\circledR}$ was used as the platform for validating this model, so that the validated model was targeted to be built in GE Control Systems Toolbox box ${ }^{\circledR}$, in order to carry out the necessary simulations required for dynamic power system studies. Figure 2, represents the MATLAB ${ }^{\circledR} /$ Simulink ${ }^{\circledR}$ representation of GGOV1 model.

The Turbine/Governor model has to be linked to ad-q model of synchronous machine, which is used for determining the mechanical power of the 


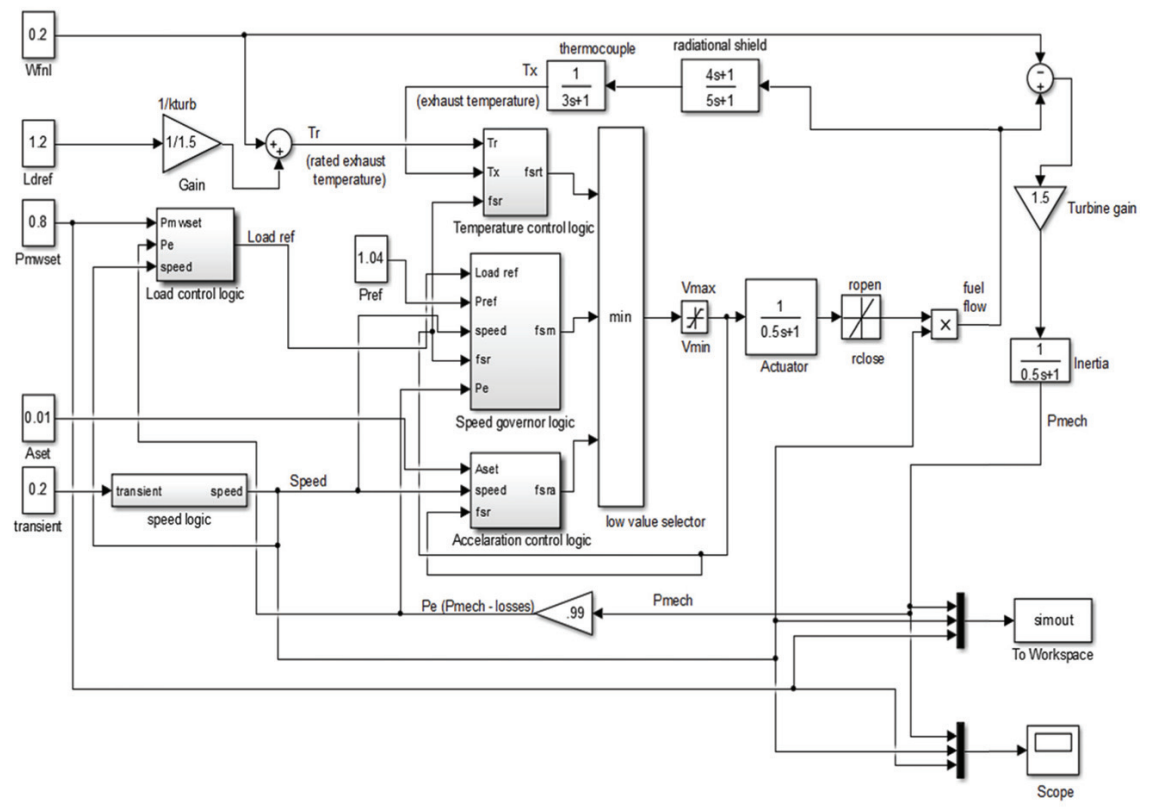

Figure 2 GGOV1 model representation in MATLAB ${ }^{\circledR} /$ Simulink ${ }^{\circledR}$.

shaft (Pmech) and the mechanical torque (Tmech) required for the generator models shown in [25].

The solver used was ode45 (Dormand-Prince) [26] for the simulation with a variable step with maximum step size of 5 ms. GGOV1 MATLAB ${ }^{\circledR /}$ Simulink ${ }^{\circledR}$ model is built with load controller (which is an integrator) incorporated, along with governor, acceleration and temperature control. In the model, as shown in Figure 2, the model was initialized with a setpoint MW value of $0.6 \mathrm{Pu}$.

Since we are defining our model with a rated droop 4\%, which means for one $\%$ change in our system frequency will make the governor to provide $25 \%$ change in MW power output, we need to make the load controller logic which works accordingly with the speed droop characteristic incorporated, so that the load controller will provide a regulated output in accordance with the changes in frequency. Load controller used here is similar to lcfb1 controller [8]. Here, the power controller reset gain (Kimw) is taken as 0.02. The rate, at which mechanical power output (Pmech) follows the setpoint value (Pmwset), depends on Kimw (i.e. If Kimw is less, Pmech follows Pmwset fast \& vice versa is also true). 
From Figure 3, in case a transient occurs, change in speed is multiplied with a gain and load controller provides a load reference (Pref1) to the governor which is equal to the reciprocal of droop (i.e. for $4 \%$ droop setting, gain will be 25 which is same to the change in power output $\%$ for the droop setting provided). The speed droop characteristic will come into action. If load controller is not being used, Kimw will be zero, thereby; load reference (Pref1) will be equal to zero and speed reference (Pref0) will be active. If Pref0 is active, speed reference (Pref) will be taken as Pref0 only, which will vary according to the speed droop logic and not a fixed value.

After the load controller section, comes the speed governor section of the model shown in Figure 3, where the speed controller or fsrn regulator was provided with PI controller logic. Here, as we made the load controller in action, the speed reference (Pref) is taken as a constant, which is equal to sum of our rated speed and rated droop (i.e. 1.04 Pu), when load controller is active. Otherwise Pref will be equal to Pref0 as mentioned above. The main key point of this section is that, a feedback from the electrical power $(\mathrm{Pe})$ incorporated

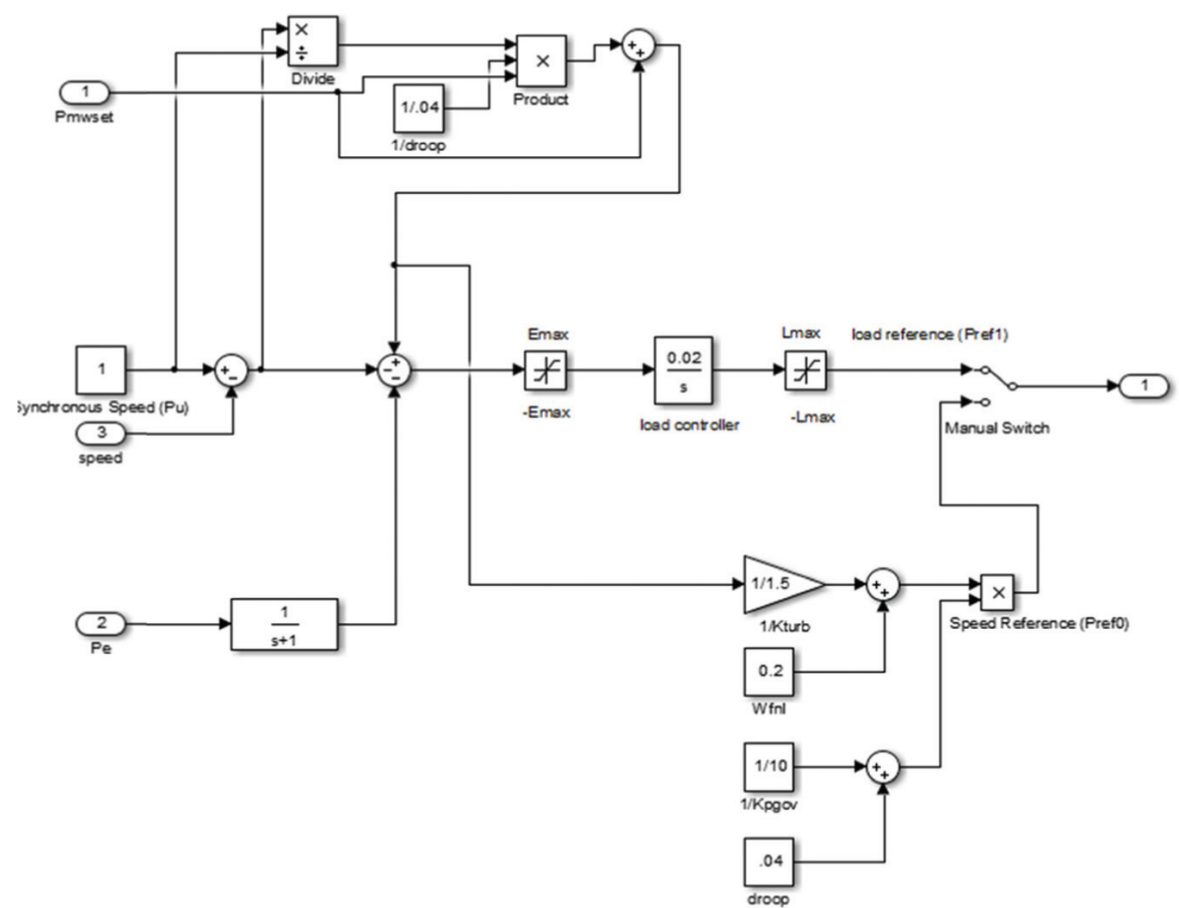

Figure 3 Load control section of GGOV1 MATLAB ${ }^{\circledR} /$ Simulink $^{\circledR}$ model. 


\section{A. S. Menon et al.}

with the rated droop as gain has been provided to the speed governor, along with the speed feedback.

The logic is that, when a frequency transient occur, the electrical power will be changing (i.e. When speed decreases, electrical power increases \& vice versa), and load controller will be providing a regulated output (load ref) to the speed governor. At the speed governor section, the negative feedback of electrical power $(\mathrm{Pe})$ equal will be also changing. Since speed droop characteristic is a logic defined for neutralizing the deviation in frequency occurred in the grid, by changing the load correspondingly, thereby bringing the system back to steady state condition, we can see that in the above model, load controller output (load ref) and electrical power feedback to the speed governor, both incorporated with droop logic, will work to neutralize the frequency transient occurred, thereby bringing the system back to steady state.

The speed governor being used is made according to the PI regulator logic implemented as shown in Figure 5, where the proportional controller with gain

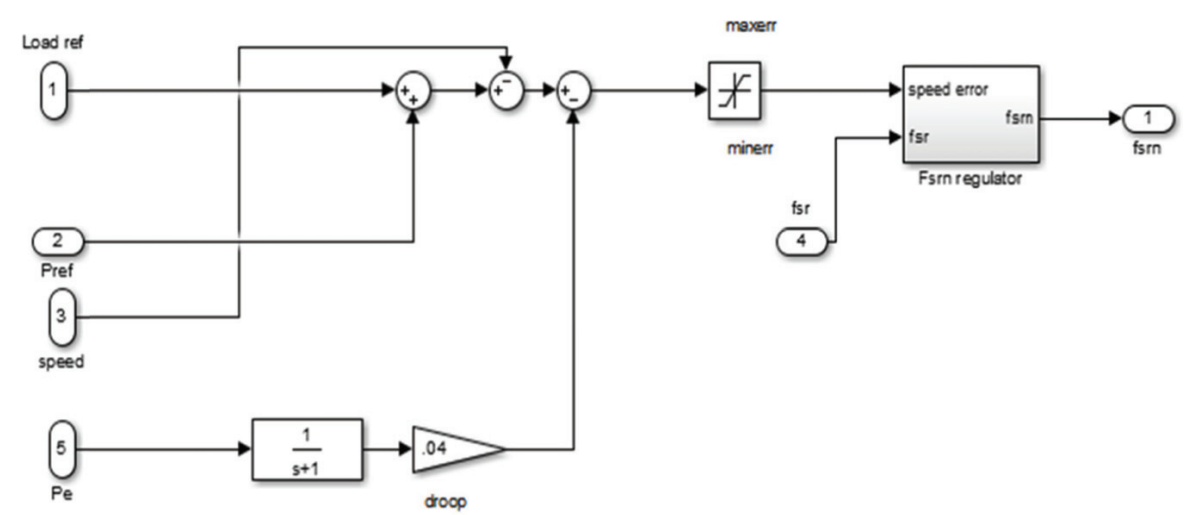

Figure 4 Speed governor section of GGOV1 MATLAB ${ }^{\circledR} /$ Simulink ${ }^{\circledR}$ model.

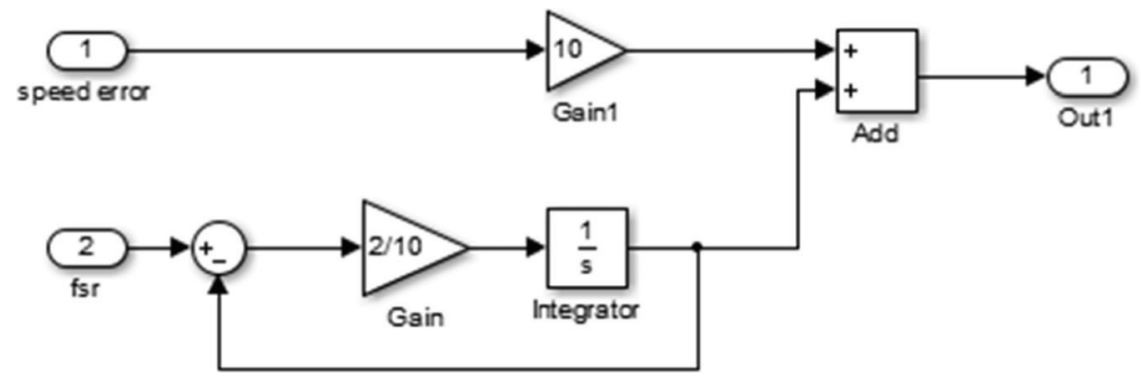

Figure 5 Speed controller section of GGOV1 MATLAB ${ }^{\circledR} /$ Simulink ${ }^{\circledR}$ model. 


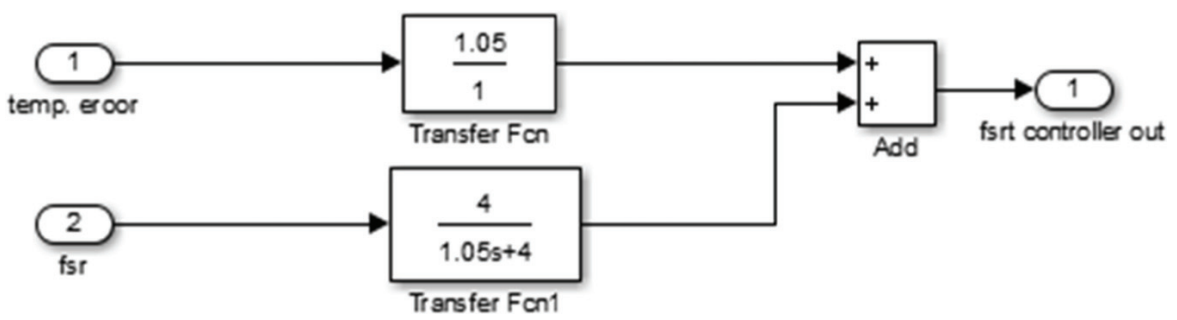

Figure 6 Temperature controller section of GGOV1 MATLAB ${ }^{\circledR} /$ Simulink ${ }^{\circledR}$ model.

(Kpgov) accounts for the present values of speed error, and the Kigov/Kpgov controller works with feedback of the signal "fsr" provided as an input for incorporating inherently the tracking logic among the three controllers feeding into the low value select gate.

The temperature controller which is frequently used in grid Simulation related studies comes into action, once the machine reaches the load limit (Ldref). For GGOV1 model, since exhaust temperature limit also is determined by maximum fuel flow, once the machine reaches the load limit (Ldref), temperature controller will come into action, thereby maintaining the turbine operation in the allowable limits. Figure 6 , shows the temperature controller or fsrt regulator implemented in GGOV1 MATLAB ${ }^{\circledR} /$ Simulink ${ }^{\circledR}$ model, which is the same PI regulator logic used for speed controller, which is activated at load limit (Ldref) equal to 1.2 Pu. Here also, a proportional controller with gain (Kpload) accounts for the present values of exhaust temperature error, and the Kiload/Kpload controller works with feedback of the signal "fsr" provided as an input for incorporating inherently the tracking logic among the three controllers feeding into the low value select gate.

The acceleration controller or fsra regulator, which is required during startup of the gas turbine, will not play an important role during grid Simulation related studies. Figure 7, shows the acceleration controller logic used in GGOV1 MATLAB ${ }^{\circledR} /$ Simulink ${ }^{\circledR}$. This controller is implemented in model through a proportional controller, with acceleration is obtained in the model taking the derivative of speed, along with a first order lag filter to remove the high frequency noise components amplified during this process.

\subsection{Parameter Validation for 7F Gas Turbines}

To carry out this modelling many parameters are required. Most of the parameters taken here are obtained either through field tests or the disturbance data recordings obtained. Parameters like control mode and turbine rating can 


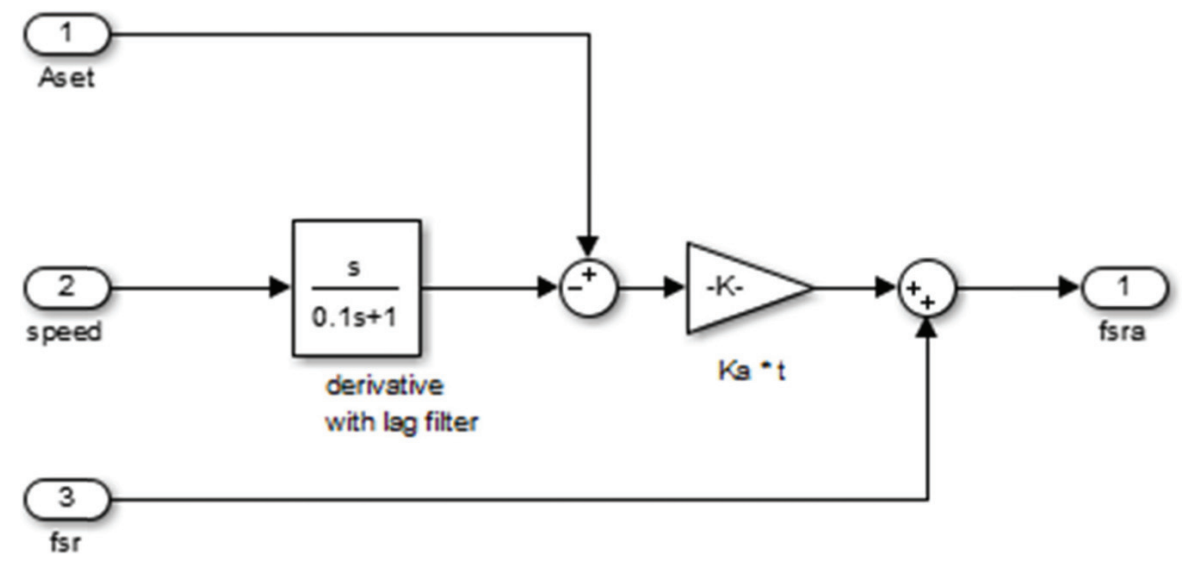

Figure 7 Acceleration controller section of GGOV1 MATLAB ${ }^{\circledR} /$ Simulink ${ }^{\circledR}$ model.

be obtained from documentation of the vendor or by the survey of controls. Some of the parameters like the minimum error, maximum error, settings of acceleration control cannot be taken from field tests or through disturbance data recordings. The values provided by the vendor are taken for this. Table 1 shows the typical values of the parameters, if better information is not obtained.

The validated parameters of $7 \mathrm{~F}$ Gas Turbine [16-20] used in the GGOV1 MATLAB ${ }^{\circledR} /$ Simulink ${ }^{\circledR}$ model, for implementing the model in the GE Control Systems Toolbox ${ }^{\circledR}$ are listed in the following table:

Table 1 7F Parameters for GGOV1 model used in MATLAB ${ }^{\circledR} /$ Simulink $^{\circledR}$

\begin{tabular}{llll}
\hline Parameter & Symbol & Unit & Value \\
\hline Permanent droop & $\mathrm{r}$ & $\mathrm{Pu}$ & 0.040 \\
Feedback signal for droop & rselect & & 1 \\
Electrical power transducer time constant & Tpelec & $\mathrm{sec}$ & 1 \\
Maximum value for speed error signal & maxerr & & 0.050 \\
Minimum value for speed error signal & minerr & & -0.050 \\
Governor proportional gain & Kpgov & & 10 \\
Governor integral gain & Kigov & & 2 \\
Governor derivative gain & Kdgov & & 0 \\
Governor derivative time constant & Tdgov & sec & 1 \\
Maximum valve position limit & vmax & & 1 \\
Minimum valve position limit & vmin & & 0.2 \\
Actuator time constant & Tact & $\mathrm{sec}$ & 0.500 \\
Turbine gain & Kturb & & 1.500 \\
No load fuel flow & Wfnl & $\mathrm{Pu}$ & 0.200 \\
Turbine lag time constant & Tb & $\mathrm{sec}$ & 0.500 \\
\hline
\end{tabular}


Table 1 Continued

\begin{tabular}{llll}
\hline Turbine lead time constant & Tc & $\mathrm{sec}$ & 0 \\
Switch for fuel source characteristic & Flag & & 1 \\
Transport lag time constant & Teng & & 0 \\
Load limiter time constant & Tfload & & 3 \\
Load limiter proportional gain & Kpload & & 1.05 \\
Load limiter integral gain & Kiload & & 4 \\
Load limiter reference value & Ldref & $\mathrm{Pu}$ & 1 \\
Speed sensitivity coefficient & $\mathrm{Dm}$ & $\mathrm{Pu}$ & 0 \\
Maximum valve opening rate & ropen & $\mathrm{Pu} / \mathrm{sec}$ & 0.100 \\
Minimum valve opening rate & rclose & $\mathrm{Pu} / \mathrm{sec}$ & -0.100 \\
Power controller (reset) gain & Kimw & $\mathrm{Pu}$ & 0.020 \\
Power controller set point (initialization) & Pmwset & & 0.6 \\
Acceleration set point & aset & $\mathrm{Pu} / \mathrm{sec}$ & 0.010 \\
Acceleration limiter gain & Ka & & 10 \\
Acceleration limiter time constant & Ta & $\mathrm{sec}$ & 0.100 \\
Speed governor dead band & db & & 0 \\
Temperature detection lead time constant & Tsa & $\mathrm{sec}$ & 4 \\
Temperature detection lag time constant & Tsb & & 5 \\
Maximum rate of load limit increase & rup & & 99 \\
Maximum rate of load limit decrease & rdown & & -99 \\
\hline
\end{tabular}

\section{Simulation Results}

The GGOV1 Turbine/Governor model implemented in MATLAB ${ }^{\circledR} /$ Simulink ${ }^{\circledR}$ with the required validations was implemented in GE Control Systems Toolbox ${ }^{\circledR}$ also. The simulation results of both were studied for different cases and closely matching results were obtained. In all cases, a small error is always present, as we are considering the generator losses (i.e. mechanical power (Pmech) \& electrical power (Pe) varies by a small amount). As we are focusing on grid Simulation related studies, the simulation is dealing with loaded conditions. Note that the machine is loaded, when the system is running at synchronous speed $1 \mathrm{Pu}$. The different simulation cases for mechanical power output for the GGOV1 Governor-Turbine model are discussed as follows:

Case 1: Mechanical power response (Pmech) for step changes provided in Pmwset

- In MATLAB ${ }^{\circledR} /$ Simulink ${ }^{\circledR} \&$ GE Control Systems Toolbox ${ }^{\circledR}$, GGOV1 model was initialized with power controller set point (Pmwset) as $0.6 \mathrm{Pu}$. Figure 8, shows the comparison of mechanical power output of turbine, when machine was loaded from 0 to $0.6 \mathrm{Pu}$. It is observe that, for the mentioned step change, an oscillatory response is obtained, where Pmech response matches closely for both. The response settles around 55-60 s 


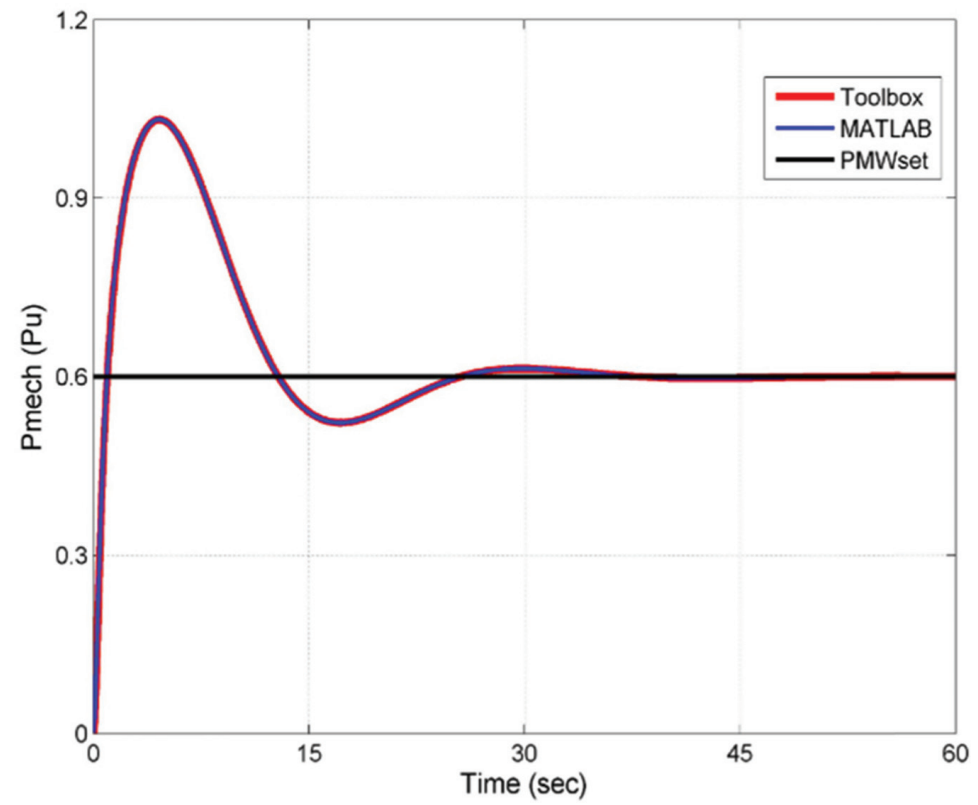

Figure 8 Acceleration controller section of GGOV1 MATLAB ${ }^{\circledR} /$ Simulink ${ }^{\circledR}$ model.

in both cases. The mechanical power response settles around 0.6061 Pu. Note that Ldref is taken as $1.2 \mathrm{Pu}$.

- A step change in power controller set point (Pmwset) was given from 0.6 $\mathrm{Pu}$ to $0.7 \mathrm{Pu}$. The mechanical power output response for MATLAB ${ }^{\circledR /}$ Simulink ${ }^{\circledR} \&$ GE Control Systems Toolbox ${ }^{\circledR}$ were matching closely as shown in Figure 9. The response got settled around $50 \mathrm{~s}$, at 0.7071 $\mathrm{Pu}$ for both the cases. The same kind of response is obtained for $10 \%$ step change in load before the load limit reference value is reached (i.e. 1.2 Pu). Till 1.2 Pu, speed/load controller will be in action.

- When a $10 \%$ step change in power controller set point (Pmwset) is given to reach the load limit value "Ldref" (1.1 Pu to 1.2 Pu), the response will settle at 1.2 Pu itself around $7 \mathrm{~s}$ for both cases, as shown in Figure 10. This happens because, the turbine power is limited by this limit "Ldref" that is frequently imposed by a curve relating the exhaust temperature to several internal engine variables, and the corresponding limiting power will vary with ambient temperature. Beyond this value, if we try to increase the load, the turbine power will not change, as maximum fuel limit will be reached. 


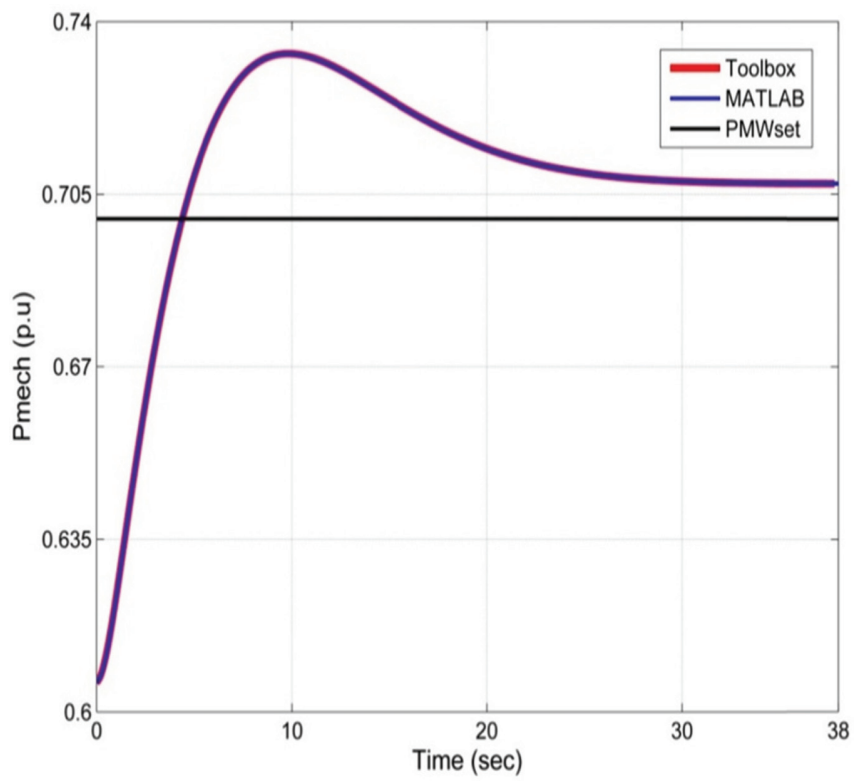

Figure 9 Generated Power (for step increase of load from 0.6 to $0.7 \mathrm{Pu}$ ).

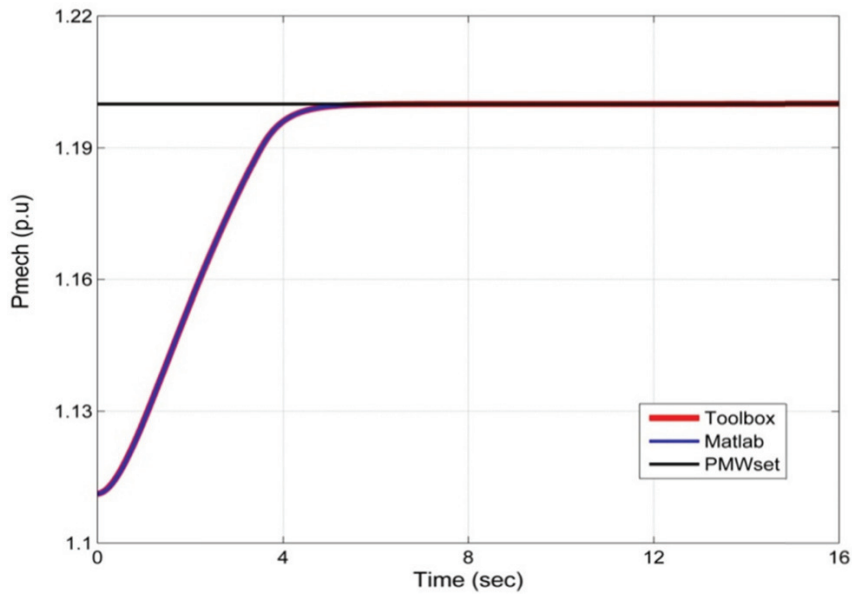

Figure 10 Generated Power (for step increase of load from 1.1 Pu to 1.2 Pu (Ldref)).

- A step change in power controller set point (Pmwset) was given from $1.2 \mathrm{Pu}$ (Load limit value) to $0.9 \mathrm{Pu}$ as shown in Figure 11. Once the mechanical power reaches load limit value, temperature controller 


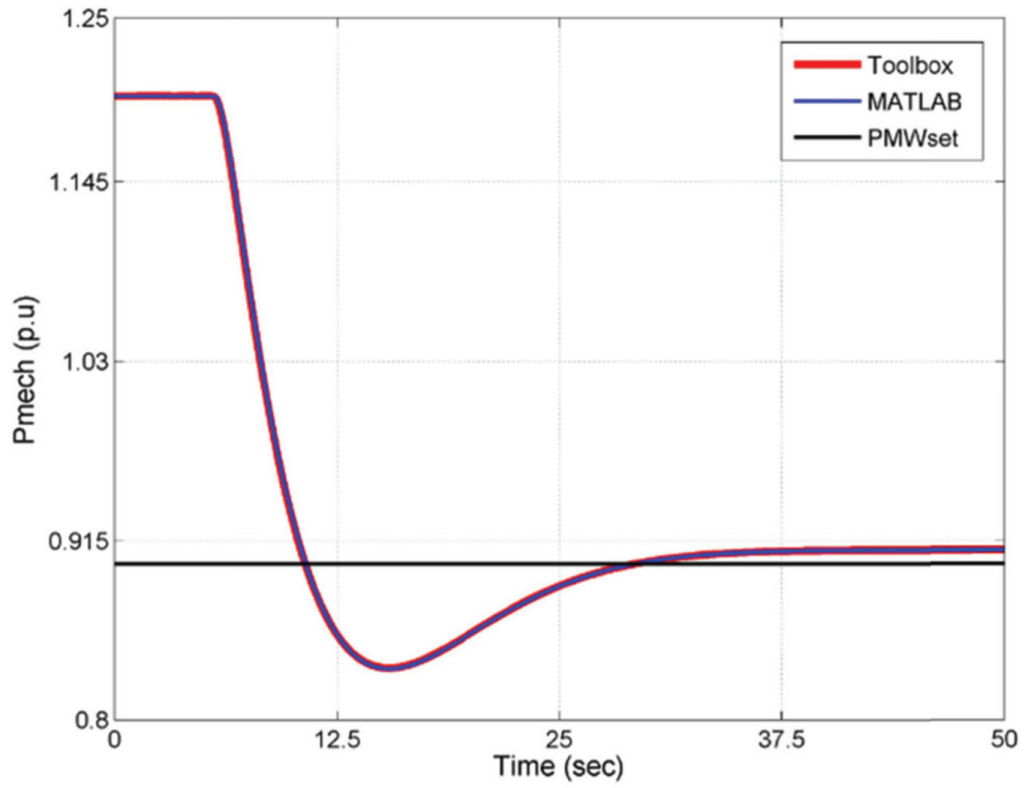

Figure 11 Generated Power (for step decrease of load from 1.2 Pu (Ldref) to 0.9 Pu).

gets active. As a result, it will take a while for the power output to change from 1.2 $\mathrm{Pu}$ (almost 6 seconds). Mechanical power immediately statrs changing from $1.2 \mathrm{Pu}$, once speed/load controller gets active.

Case 2: Mechanical Power response (Pmech) for frequency transients in the grid

- A frequency deviation of $-0.2 \mathrm{~Hz}(-0.0033 \mathrm{Pu})$ shown in Figure 12, which is the minimum limit of the transient with which GGOV1 can be used, was given when the turbine was running at $60 \mathrm{~Hz}$ (rated) or $1 \mathrm{Pu}$. The frequency transient occurs for a period of $60 \mathrm{~s}$, and the mechanical power output response (Pmech) for the transient shown in Figure 12 responded with a $10 \%$ increase in load, as the response behaves inversely proportional to the change in transient due to the speed droop characteristic. Once the transient settles to $1 \mathrm{Pu}$, Pmech also settles to its steady state.

- Afrequency deviation of $+0.2 \mathrm{~Hz}(+0.0033 \mathrm{Pu})$ shown in Figure 13, which is the maximum limit of the transient with which GGOV1 can be used, 

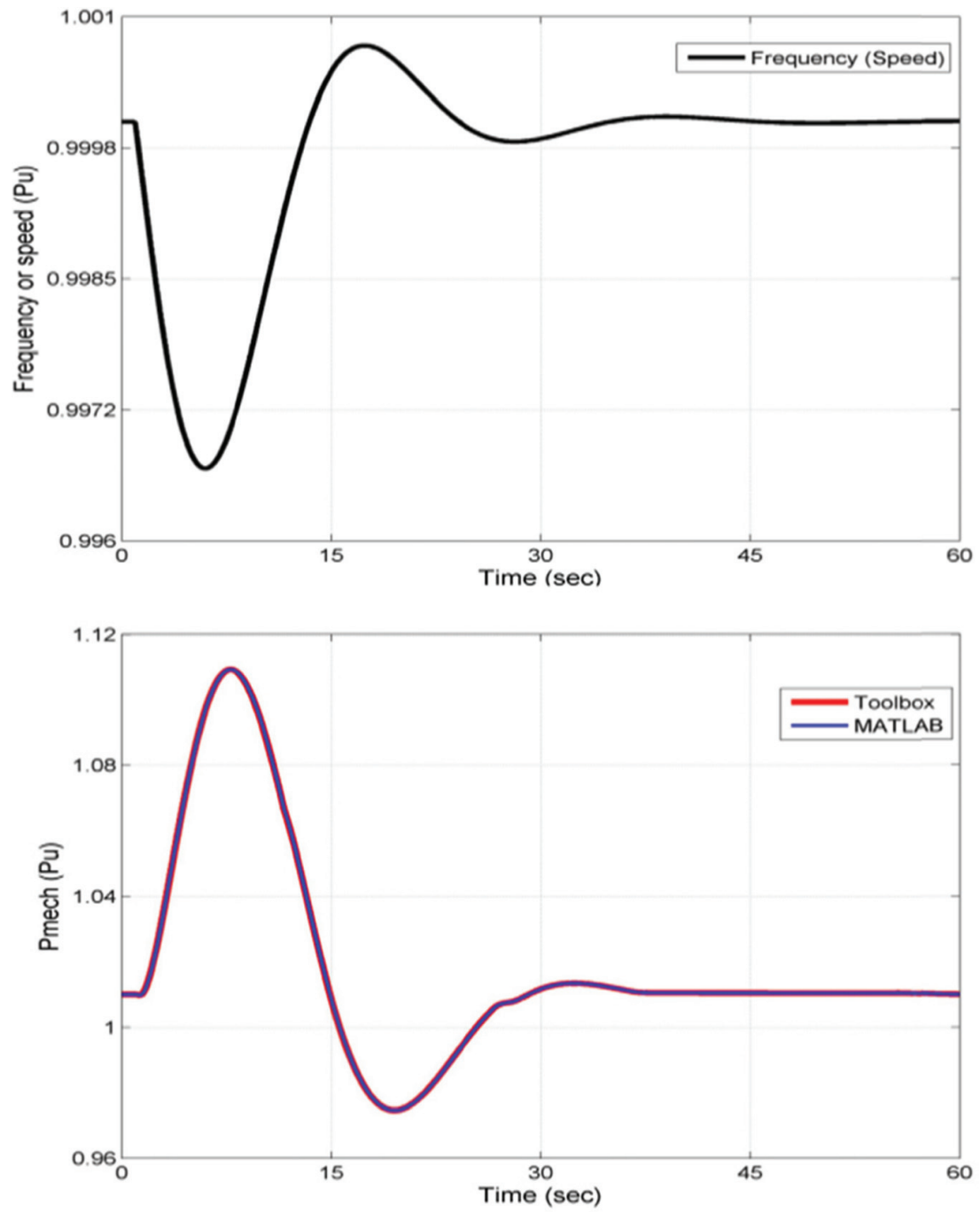

Figure 12 Generated Power for a frequency transient of $-0.2 \mathrm{~Hz}(-0.0033 \mathrm{Pu})$.

was given when the turbine was running at $60 \mathrm{~Hz}$ (rated) or $1 \mathrm{Pu}$ The frequency transient occurs for a period of $60 \mathrm{~s}$, and the mechanical power output response (Pmech) for the transient shown in Figure 13 responded with a $10 \%$ dip in load, as the response behaves inversely proportional to the change in transient due to the speed droop characteristic. 

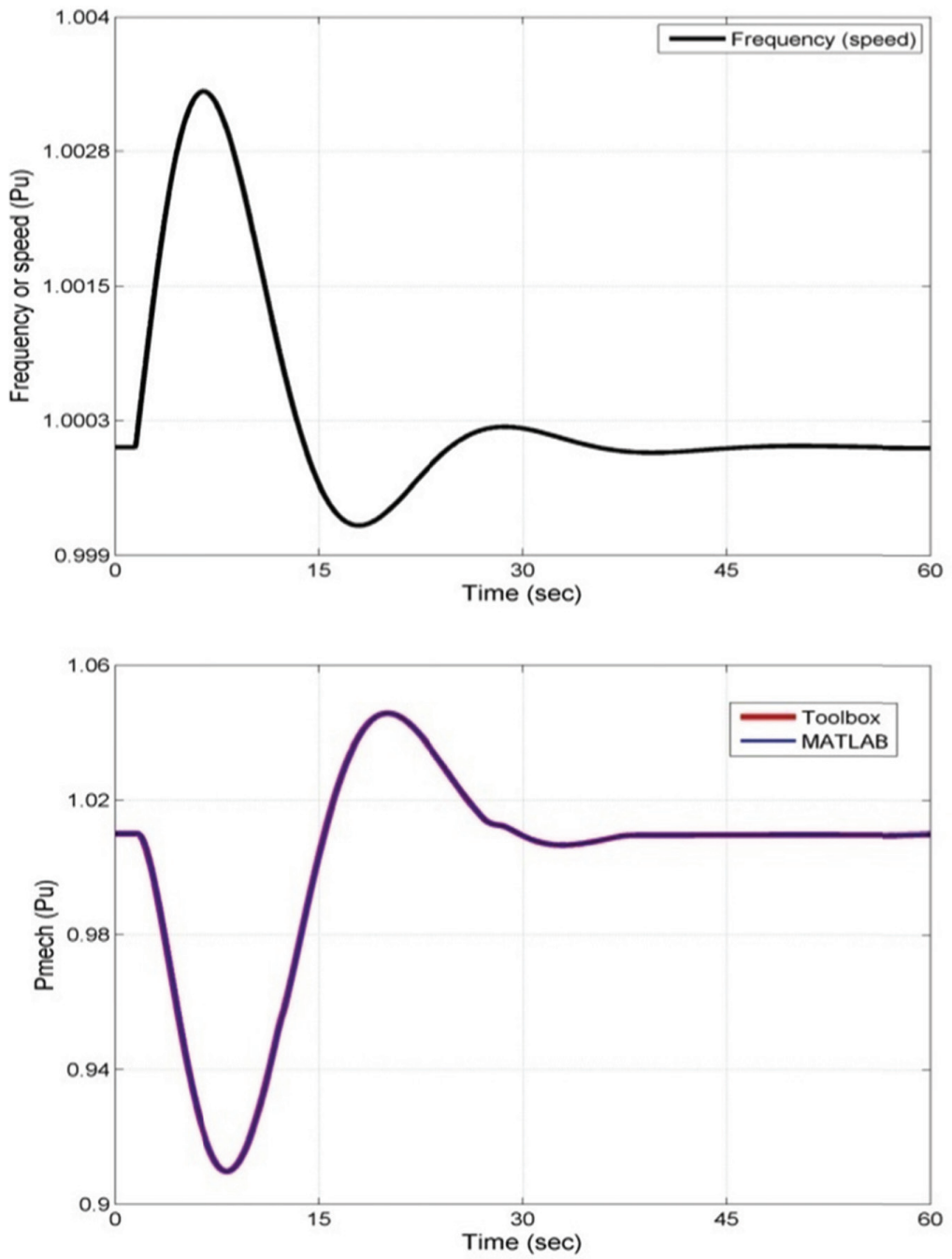

Figure 13 Generated Power for a frequency transient of $+0.2 \mathrm{~Hz}(+0.0033 \mathrm{Pu})$.

\section{Conclusion}

The main target of the study was to focus on the development of the GE GGOV1 turbine/governor model in GE Control Systems Toolbox ${ }^{\circledR}$ in order to carry out grid simulation studies. For this purpose, the model was made in MATLAB ${ }^{\circledR} /$ Simulink ${ }^{\circledR}$ and necessary validations were done, in order to obtain similar kind of response in GE Control Systems Toolbox ${ }^{\circledR}$. 
The simulation of the models developed was completed successfully and the GE GGOV1 turbine/governor model in GE Control Systems Toolbox ${ }^{\circledR}$ can be used for integrating to Electrical Models, for more accurate Simulation studies.

In order to carry out different kinds of power system stability studies, it is required to develop a dynamic load flow algorithm of the grid, to which the GE GGOV1 turbine/governor model made has to be incorporated for proactively positioning the turbine, according to the grid conditions. Also, validated parameters for GGOV1 turbine/governor model provided in this report are for 7F Gas turbine frames.

\section{References}

[1] Kundur, P., Paserba, J., Ajjarapu, V., Andersson, G., Bose, A., Canizares, C., Hatziargyriou, N., Hill, D., Stankovic, A., Taylor, C., and Van Cutsem T. (2004). Definition and classification of power system stability IEEE/CIGRE joint task force on stability terms and definitions. IEEE Trans. Power Syst. 19, 1387-1401.

[2] Demello, F. P., and Concordia, C. (1969). Concepts of synchronous machine stability as affected by excitation control. IEEE Trans. Power Apprat. Syst. 88, 316-329.

[3] Kundur, P. (1994). Power System Stability and Control. New York: McGraw Hill.

[4] Pourbeik, P. (2013). "Dynamic models for turbine-governors in power system studies," in IEEE Task Force on Turbine-Governor Modeling. Technical Report PES-TR1.

[5] Mantzaris, J., and Vournas, C. (2007). Modelling and stability of a single-shaft combined cycle power plant. Intl. J. Thermodynamics. 10, 71-78.

[6] Mantzaris, J., Karystianos, M., and Vournas, C. (2008). "Comparison of gas turbine and combined cycle models for system stability studies," in 6th Mediterranean Conference on MedPower, Thessaloniki, Greece, 61400-27.

[7] Shalan, H. E., Hassan, M. M., and Bahgat, A. B. G. (2011). Parameter estimation and dynamic simulation of gas turbine model in combined cycle power plants based on actual operational data. J. Am. Sci. 7, 303-310.

[8] Pereira, L., Undrill, J., Kosterev, D., Davies, D. and Patterson, S. (2003). A new thermal governor modeling approach in the WECC. IEEE Trans. Power Syst. 18, 819-829. 
[9] Krishan, O. (2016). "Frequency regulation in a standalone winddiesel hybrid power system using pitch-angle controller," in International Conference on Computing for Sustainable Global Development (INDIACom), 1148-1152.

[10] Salih, H. W., Wang, S., Farhan, B. S., and Waqar, A. (2016). "PSO tuned fuzzy based pitch blade controller of grid-tied variable speed wind turbine," in International Conference on Industrial Electronic Application (ICIEA), 737-742.

[11] Abo-Al-Ez, K. M., and Tzoneva, R. (2016). "Active power control (APC) of PMSG wind farm using emulated inertia and droop control," in International Conference on Industrial and Commercial Use of Energy (ICUE), 140-147.

[12] Tavakoli, P., Vaezi, N., and Sani, S. K. H. (2015). "Design MVSTR pitch controller for $100 \mathrm{KW}$ wind turbine," International Conference on Technology, Communication and Knowledge (ICTCK), 299-305.

[13] Hou, G., Jiang, Z., Yang, Y., and Zhang, J. (2016). "Variable universe fuzzy controller used in MPPT based on DFIG wind energy conversion system," in International Conference on Control and Decision Conference (CCDC), 5871-5875.

[14] Kumar, S. S., Xavier, R. J., and Balamurugan, S. (2016). "Small signal modelling of gas turbine plant for load frequency control," in Biennial International Conference on Power and Energy Systems: Towards Sustainable Energy (PESTSE), pp. 1-5.

[15] Viveiros, C., Melício, R., Igreja, J. M., and Mendes, V. M. (2014). "Fuzzy, integer and fractional-order control: application on a wind turbine benchmark model," in International Conference on Methods and Models in Automation and Robotics (MMAR), 252-257.

[16] Maneesh. (2015). "Frequency control of a microgrid by using PI controller," in International Conference on Energy, Power and Environment: Towards Sustainable Growth (ICEPE), 1-5.

[17] Surendran, S., Chandrawanshi, R., Kulkarni, S., Bhartiya, S., Nataraj, P. S., and Sampath, S. (2016). "Model predictive control of a laboratory gas turbine," In Indian Control Conference (ICC), 79-84.

[18] Senani, F., Rahab, A., Louar, F., Bourourou, F., and Benalla, H. (2015). "Active and reactive power control of DFIG using PI and DPC controllers," in International Conference on Electrical Engineering (ICEE), 1-6. 
[19] Woodward, J. L. (1968). Hydraulic-turbine transfer function for use in governing studies. Elect. Eng. 115, 424-426.

[20] Arthur R.. Bergen and Vittal, V., (2000). Power systems analysis. Upper River Saddle, NJ: Prentice Hall.

[21] Pourbeik, P. Agarwal, B. K., Bourque, E., and Schneider, A. (2007). "Interconnected Power System Response to Generation Governing: present Practice and Outstanding Concerns," in IEEE Special Publication 07TP180 IEEE Task Force.

[22] Pourbeik, P., Baba, Z., and Boyer, R. (2003). "Modeling of gas turbines and steam turbines in combined-cycle power plants," in CIGRE Technical Brochur, 238.

[23] Kunitomi, K., Kurita, A., Okamoto, H., Tada, Y., Ihara, S., Pourbeik, P., Price, W. W., Leirbukt, A. B. and Sanchez-Gasca, J. J. (2001). "Modeling frequency dependency of gas turbine output," in Intnational Conference on Power Engineering Society Winter Meeting, Vol. 2, 678-683.

[24] Pourbeik, P. (2002). "The dependence of gas turbine power output on system frequency and ambient conditions", in CIGRE Session, Vol. 38, 5 .

[25] "Turbine-Governor Models", Standard Dynamic Turbine-Governor Systems in NEPLAN Power System Analysis Toolbox.

[26] MathWorks, Inc. 2005. MATLAB: the language of technical computing. Desktop tools and development environment, version 7, Vol. 9. Natick, MA: MathWorks.

[27] Rowen, W. I. (1983). Simplified mathematical representations of heavyduty gas turbines. J. Eng. Power. 105, 865-869.

[28] Undrill, J. M., and Woodward, J. L. (1967). Nonlinear hydro governing model and improved calculation for determining temporary droop. IEEE Trans. Power Apparat. Syst. 4, 443-453.

[29] Concordia, C., Kirchmayer, L. K., De Mello, F. P., and Schluz, R. P. (1966). "Effect of prime mover response and governing characteristics on system dynamic performance," in Proceeding American Power Conference.

[30] Endale Turie, S. (2012). Gas Turbine Plant Modeling for Dynamic Simulation. 2011 Master of Science Thesis, KTH School of Industrial Engineering and Management, Stockholm. 


\section{Biographies}

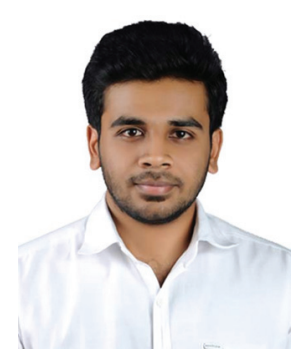

Akhil S. Menon, he holds a Bachelor's degree in Electrical and Electronics Engineering from Mahatma Gandhi University and Master's degree in Control and Automation from VIT University, India. He is currently working as Assistant Professor at Sree Narayana Institute of Technology, Kerala and worked as an intern at GE Power. His area of interest is Control and Automation.

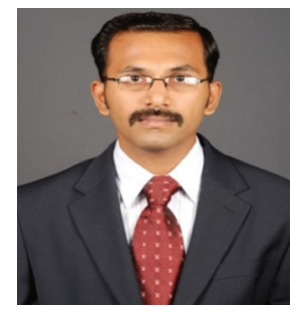

N. Ramesh Babu, he received his bachelor's degree in Electrical and Electronics Engineering in Bharathiar University, India and received his master's degree in Applied Electronics from Anna University, India. Also he obtained his Ph.D. degree from VIT University, India. He has published several technical papers in national and international conferences and international journals. His current research includes Wind Speed Forecast, Optimal Control of Wind Energy Conversion System, Solar Energy and Soft Computing techniques applied to Electrical Engineering. 


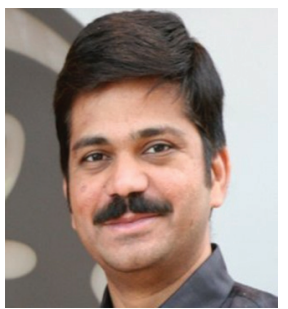

Sreedhar Desabhatla, he holds a bachelor's degree in Electrical and Electronics Engineering in Jawaharlal Nehru Technical University, India. He is presently working as a Principal Engineer at GE Power, Munich, Germany. He has 8 US patents in his credit and 12 patents filed in the area of power and energy. His area of interest is design of controllers for generators, power converters for wind and solar energy system and control drives. 
